City University of New York (CUNY)

CUNY Academic Works

\title{
The Bar Exam and the COVID-19 Pandemic: The Need for Immediate Action
}

Claudia Angelos

New York University School of Law

Sara J. Berman

AccessLex Institute Center for Legal Excellence

Mary Lu Bilek

CUNY School of Law

Carol L. Chomsky

University of Minnesota Law School

Andrea A. Curcio

Georgia State University School of Law

See next page for additional authors

\section{How does access to this work benefit you? Let us know!}

More information about this work at: https://academicworks.cuny.edu/cl_pubs/340

Discover additional works at: https://academicworks.cuny.edu

This work is made publicly available by the City University of New York (CUNY).

Contact: AcademicWorks@cuny.edu 


\section{Authors}

Claudia Angelos, Sara J. Berman, Mary Lu Bilek, Carol L. Chomsky, Andrea A. Curcio, Marsha Griggs, Joan W. Howarth, Eileen Kaufman, Deborah Jones Merritt, Patricia E. Salkin, and Judith Welch Wegner 


\section{The Bar Exam and the COVID-19 Pandemic: The Need for Immediate Action}

Claudia Angelos, Sara J. Berman, Mary Lu Bilek, Carol L. Chomsky, Andrea A. Curcio, Marsha Griggs, Joan W. Howarth, Eileen Kaufman, Deborah Jones Merritt, Patricia E. Salkin, Judith Welch Wegner ${ }^{1}$

March 22, 2020

The novel coronavirus COVID-19 has profoundly disrupted life in the United States. Schools and universities have closed throughout much of the country. Businesses have shuttered, and employees are working from home whenever possible. Cities and states are announcing lockdowns in which citizens may leave their homes only for vital errands or exercise.

Medical experts advise that at least some of these restraints will continue for 18 months or more-until a vaccine is developed, tested, and administered widely. ${ }^{2}$ It is possible that localities will be able to lift some of these restrictions (such as lockdowns and school closures) intermittently during those months, but other restraints (social distancing, limits on large gatherings) are likely to continue for a year or more.

Under these conditions, jurisdictions will not be able to administer the July 2020 bar exam in the usual manner. Even if some of the most rigorous restrictions have been lifted by July 28 , prohibitions on large gatherings are likely to remain. Attempting to administer the bar exam to hundreds of test takers in a single room would endanger the test takers, staff administering the exam, and the public health. ${ }^{3}$ The variation in jurisdictional outbreaks and public health responses may also compromise the ability to set a single test date across the country.

At the same time, it is essential to continue licensing new lawyers. Each year, more than 24,000 graduates of ABA-accredited law schools begin jobs that require bar admission. ${ }^{4}$ The legal system depends on this yearly influx to maintain client service. The COVID-19 crisis, moreover, will dramatically increase the need for legal services, especially among those who can least afford those services. We cannot reduce entry to the profession at a time when client demand will be at an all-time high.

\footnotetext{
${ }^{1}$ We are scholars who have studied and written about licensing for many years, and who have ongoing research projects related to licensing. Based on this knowledge, we offer these preliminary ideas for jurisdictions to consider as they grapple with how to administer the July 2020 bar exam. To assist those jurisdictions, we have attempted to compile a full range of options - although individual authors might prefer some options over others. Full titles and institutional affiliations (for identification purposes only) are listed at the end of this paper.

${ }^{2}$ See, e.g., Neil M. Ferguson et al., Impact of Non-Pharmaceutical Interventions (NPIs) to Reduce COVID19 Mortality and Healthcare Demand, https://spiral.imperial.ac.uk:8443/handle/10044/1/77482 (Mar. 16, 2020). Leaders in the United States and United Kingdom have relied on this paper to design responses to the pandemic.

${ }^{3}$ There is also some question about whether the August administration of the MPRE will proceed, given the current closure of all Pearson Vue testing centers, where that test is administered. The MPRE, however, presents fewer challenges because it is an online test. We do not address the MPRE further here except to note that jurisdictions will also have to remain aware of the status of that test-perhaps granting 2020 graduates additional time to complete that or a similar exam.

${ }^{4}$ NALP, Class of 2018 National Summary Report, https://www.nalp.org/uploads/NationalSummaryReport Classof2018 FINAL.pdf. The total number of newly licensed lawyers serving clients is somewhat higher than this because some states license graduates of stateaccredited law schools. We lack immediate access to those numbers so have not included them here.
} 
We explain below why it is urgent to maintain the flow of new lawyers into the legal system, and then outline six options for sustaining that supply. As we explain, three of those options are risky and likely to fail. The other three, however, offer significant promise for assuring competent legal services to the public. Just as courts are temporarily adapting their practices to keep the justice system in place during this pandemic, we need to temporarily adapt our licensing system. We cannot afford to close the doors to the profession in these precarious times.

\section{The Need for New Lawyers}

In 2018, the most recent year for which we have data, 24,398 graduates of ABA-accredited law schools took jobs that required bar admission. ${ }^{5}$ Almost half of those jobs $(48.6 \%)$ were with government $(2,725)$; public-interest organizations $(1,812)$; firms of 1-10 lawyers $(5,556)$; and firms of $11-25$ lawyers $(1,763)$. Employers in these four categories rely heavily on new lawyers to meet client needs. In fact, some members of the law school class of 2020 are already working for these employers - with the employers eagerly awaiting their transition to full-time, fully licensed lawyers.

These four groups of employers, notably, tend to serve the needs of low-income individuals, middleincome individuals, and small businesses. Disrupting the flow of new lawyers into these workplaces will undermine service to groups that already struggle to obtain services from our legal system.

Although the need for new lawyers is most acute among government, public interest organizations, and small firms, larger law firms also rely heavily on new lawyers. These firms pared associates after the 2009 recession, increasing their reliance on each class of new associates they hire. Associates today bill almost as many hours per month as they did before the recession. ${ }^{6}$ Data from an ongoing research project, furthermore, shows that first-year lawyers at large firms perform many tasks (such as attending hearings and rendering advice directly to clients) that require a law license. ${ }^{7}$

Most important, the COVID-19 crisis almost certainly will increase demand for all types of legal services. Businesses are experiencing unprecedented closures and other disruptions. Employees in broad segments of the economy have already lost jobs; more will do so. The working poor, with few assets or employmentrelated benefits, have been particularly hard hit. Families are suffering from lost income, diminished savings, and increased needs to care for their children and elderly members. Soon, many of these families will suffer from the death of a loved one.

Lawyers will be essential to help these individuals access housing, food, and government assistance. Clients will also have heightened needs for legal advice related to employment loss, loans, health care, insurance disputes, disability benefits, family stresses, civil rights, and estate planning. Critical issues

\footnotetext{
${ }^{5}$ Id. Information about the Class of 2019 should be available from the ABA by mid-April, but employment numbers have been relatively constant for several years; the Class of 2018 provides an appropriate guide.

${ }^{6}$ Georgetown LaW Center on Ethics and the Legal Profession \& Thomson Reuters Legal Executive InStitute, 2020 Report ON THE StATE OF THE Legal MARKET 8 (2020),

https://legalprof.thomsonreuters.com/LEI 2020 State of Legal Market LP 010620?cid=9014946\&sfdccampaign id=70140000000vXWtQAM\&chl=tr.

${ }^{7}$ IAALS, Building a Better Bar: Capturing Minimum Competence, https://iaals.du.edu/projects/building-a-betterbar. Several of us are directly involved in this research project, which is funded by AccessLex.
} 
involving prisoners, bail, and speedy trial will mushroom in the criminal justice system. We cannot meet all of these legal needs if we abruptly shut off the supply of new lawyers.

The Model Rules of Professional Conduct stress that lawyers must improve "access to the legal system, the administration of justice and the quality of service rendered by the legal profession." ${ }^{8}$ Each lawyer should also "be mindful of deficiencies in the administration of justice and of the fact that the poor, and sometimes persons who are not poor, cannot afford adequate legal assistance. ${ }^{\prime 9}$ During this global crisis, we should do everything in our power to maintain the supply of legal services.

Our 2020 graduates have knowledge and skills that will be particularly helpful in responding to the legal needs of a population stricken by COVID-19. In addition to their three years of legal education, these graduates are fully equipped to function online-a skill that some senior lawyers still lack. ${ }^{10}$ Without licenses, however, these graduates languish in an employment limbo. A substantial number of law graduates rely upon bar passage to secure employment. ${ }^{11}$ Without an opportunity to obtain a license by fall, as the July bar exam allows, these graduates face months of uncertainty, unemployment, and financial hardship. Those burdens will fall disproportionately on graduates from groups that are already underrepresented in the legal profession, further hindering our efforts to diversify the profession. Rather than abandon the Class of 2020 to this fate, we can tap their critical skills to serve urgent legal needs.

\section{Options for Licensing}

Public health concerns likely will prohibit administration of the July 2020 bar exam in large arenas. We assess here six possible alternatives. The first three appear likely to fail, but each of the other three offers considerable promise.

1. Postponement. Postponing the July exam until fall 2020 offers some initial appeal. This strategy, however, is very likely to fail. The best scientific models of COVID-19 suggest that the United States will suffer several waves of infection. ${ }^{12}$ This is exactly what happened during the influenza pandemic of 1918-19. The first wave of that pandemic occurred during the spring of 1918, followed by subsidence over the summer, and then a second-much more deadly-wave that began in August 1918.

Public health measures, unfortunately, cannot prevent these waves. In fact, those measures purposely harness the waves to spread out the burden on hospitals and health care workers. As jurisdictions start to lift their most restrictive public health measures in summer 2020, a second wave

\footnotetext{
${ }^{8}$ MOdel Rules of PROF'L CONdUCt preamble [6].

${ }^{9} / d$.

${ }^{10}$ A particularly sobering prospect is that, as the pandemic continues, some lawyers over the age of 60 may need to limit their work to protect their own health. These lawyers may be able to conduct work online but not meet personally with clients, attend live hearings, or negotiate in person. If those limits persist for 18 months or more, as current projections suggest, employers will have even greater need of new lawyers to maintain client service. ${ }^{11}$ The number of graduates employed at graduation varies widely among law schools, from a low of $8.3 \%$ to a high of 94.9\%. Publiclegal, Law School Rankings-Employed at Graduation, https://www.ilrg.com/rankings/law/1/desc/EmployGrad (last visited Mar. 22, 2020). More than half of all law schools, however, report at-graduation employment rates of less than $50 \%$ or fail to report that rate. Id. Some of these graduates may obtain jobs without first securing a license, but many need that license to find employment. 12 Ferguson et al., supra note 2.
} 
of COVID-19 likely will begin. As infections rise, cities and states will likely reinstitute more restrictive measures-producing a series of waves until an effective treatment or vaccine is widely available.

The probable wave-like nature of the pandemic means that it is impossible to predict a time in 2020 when any jurisdiction could safely schedule an exam administered to large groups of people. Postponing the exam until early fall 2020, in fact, might situate the exam squarely in the second wave of the disease. Postponing and then cancelling the exam would be devastating for bar exam offices, exam-takers, employers, low-income clients, and small businesses. Exam offices in many jurisdictions are leanly staffed and funded; asking those offices to prepare for a postponed exam, only to have it cancelled and perhaps rescheduled, might overwhelm those offices. Exam-takers, meanwhile, would have already weathered a summer of intense study-many of them without employment or payand would then face additional months of unemployment and uncertainty. Employers and the most vulnerable clients would face greatly increased legal demands without new lawyers to assist them.

2. Online Exams. Jurisdictions could attempt to offer the July 2020 bar exam entirely online. The feasibility of this option would rest largely on the National Conference of Bar Examiners (NCBE)'s ability to move the Uniform Bar Exam (UBE) and each of its components (which some jurisdictions use separately) online. Non-UBE jurisdictions would also have to move their local components online. Even if this is possible in the relatively short time remaining before July, questions would remain about providing appropriate exam security and health precautions. Could test-takers access the exam from home computers? If so, will all of them have necessary internet access and quiet locations for testtaking? If test-takers need to visit testing centers, will those centers offer enough capacity to accommodate the large number of test-takers? Will the testing centers offer sufficient health precautions? A sudden move to online exams could also raise questions about equating scores to previous written exams. Given the need to make decisions quickly (see below), it would be very risky to rely on this alternative.

3. Exams Administered to Small Groups. In at least some jurisdictions, it might be possible to administer the bar exam in multiple locations, with no more than 10 test-takers in each room. This would require considerable advance planning and significantly more exam proctors than most jurisdictions currently use. Provision would also have to be made for candidates with higher health risks (e.g., those with immunocompromised systems) to take the exam in solo rooms; this would add to the significant logistical complexities bar examiners already handle in administering accommodated exams to those with disabilities. Offering the exam to small groups, except in the smallest states, is likely to significantly increase costs.

This option is particularly risky because, even if a jurisdiction could surmount the logistical and financial challenges, it is impossible to predict the status of public health restrictions in any locality during late July. Those restrictions may even vary within states. As explained above, we will experience waves of disease and stringent public health measures for the foreseeable future. If a city or state is in a lockdown period, then even small-group administration would be forbidden. Time spent planning for this type of administration might be wasted time at best. 
4. Emergency Diploma Privilege. Wisconsin has long used a diploma privilege, which licenses most graduates of the state's schools without the need to take a bar exam. ${ }^{13}$ This system has worked well for Wisconsin. ${ }^{14}$ Given that success, other jurisdictions should consider implementing an emergency diploma privilege to meet this once-in-a-century pandemic. ${ }^{15}$ The privilege could extend solely to graduates of the class of 2020 (including those who graduated in December 2019) from accredited law schools. Individuals who had previously taken and failed a bar examination in any state could be excluded.

If adopted in its pure form, this option would allow graduates to practice only in the jurisdiction where they attended law school. That constraint would hamper efforts to serve clients, and would be particularly problematic for graduates (and their employers) who have already accepted jobs in other states. Given the large number of states that already participate in the UBE, as well as the national standards that ABA-accredited law schools follow, jurisdictions should consider extending their diploma privilege to graduates in other jurisdictions that promise reciprocity on this emergency measure. The advantages of providing client service and graduate employment in this crisis are immense. ${ }^{16}$

This option is straightforward and easy to administer; based on Wisconsin's experience, risks to the public are minimal. It would also be the most efficient way to get teams of licensed new lawyers on the front lines to help meet the legal challenges faced by our society as we first wage war to combat the virus and then rebuild profoundly damaged economic, social, and legal systems.

5. Emergency Diploma Privilege-Plus. Jurisdictions could tighten eligibility for the emergency diploma privilege (Option 4) by adding one or more other requirements to this emergency measure. Examples include:

- Completion of online courses or exams that the state has developed to supplement the UBE.

- Law school certification of additional educational credentials, such as successful completion of a clinic or externship. ${ }^{17}$

- Affidavit from an employer or externship supervisor that the candidate possesses the knowledge and skills to practice law with minimum competence. Law schools have developed rubrics for externships and clinical courses that could be used to guide that assessment. ${ }^{18}$

- Completion of bridge-the-gap programs.

\footnotetext{
${ }^{13}$ WIS. SUP. СT. R. 40.03. The rule requires students to complete 60 credits in standard doctrinal areas of law; 30 of those credits must be earned in specified subjects. The Wisconsin rule could provide a model for states interested in using this approach on a one-time, emergency basis.

${ }^{14}$ See Beverly Moran, The Wisconsin Diploma Privilege: Try It, You'll Like It, 2000 WIS. L. REV. 645 (2000).

${ }^{15}$ There is another precedent for adopting this approach: For many years, some states extended a diploma privilege to veterans. See Kristin Booth Glen, Thinking Out of the Bar Exam Box: A Proposal to "Maccrate" Entry to the Profession, 23 PACE L. ReV. 343, 462 (2003).

${ }^{16}$ In earlier years, some states extended their diploma privilege to graduates of all U.S. law schools. See Moran, supra note 14, at 646.

17 Many students should have completed these experiences to comply with the ABA's required 6 credits of experiential learning. For those that have not, jurisdictions might couple this option with one allowing licensure through an employer affidavit.

${ }^{18}$ Sample rubrics are available from the authors upon request.
} 
- Completion of CLE programs. States could, if desired, specify programs in areas of particular client need and/or avoidance of common entry-level pitfalls.

- Completion of MAX, a free, online financial literacy program offered by AccessLex. With uncertain employment and high debt, this program may be particularly important for 2020 graduates.

- Completion of specified CALI lessons. The Center for Computer-Assisted Legal Instruction, "CALI," maintains over 1,000 lessons on legal principles, including all subjects covered by most bar exams.

Each of these requirements adds some complications to an emergency diploma privilege, but none appear insurmountable. The requirements are all designed to offer additional assurance of a candidate's competence.

6. Supervised Practice. Many jurisdictions issue student licenses that allow advanced law students to practice under a licensed lawyer's close supervision. ${ }^{19}$ In at least some jurisdictions, those licenses extend until bar exam results are announced. Jurisdictions could temporarily modify these supervised practice rules to: (a) allow 2020 graduates of accredited law schools (including those who graduated in December 2019) to use these licenses through November 15, 2020; and (b) permit those graduates to use those licenses for any type of employer that provides close supervision by a licensed lawyer. ${ }^{20}$ Any jurisdiction that does not have a supervised practice rule could temporarily adopt one of this modified nature.

With a supervised practice rule in place, jurisdictions could then license law graduates who complete 240 hours of supervised legal work and submit an affidavit from their supervisor(s) attesting that they have successfully completed that work. Rubrics could guide both feedback to the graduates and the determination of successful completion. ${ }^{21}$

- This option would offer a particularly rigorous assessment of graduates' competence because it would require demonstration of a wide range of knowledge and skills required for practice. As NCBE's recent practice analysis shows, minimum competence includes many skills that are difficult to assess (or are not currently tested) on a written bar exam. ${ }^{22}$

- Consistent with public health guidelines, much of this work would have to occur online. Lawyers, however, are adapting quickly to the online environment and recent graduates are particularly adept with online technologies.

- To assure work for all 2020 graduates seeking licenses, jurisdictions could offer work through the ABA Free Legal Answers program, https://abafreelegalanswers.org/ or similar state-sponsored

\footnotetext{
${ }^{19}$ For information on the history and scope of these rules, see Wallace J. Mlyniec \& Haley D. Etchison, Conceptualizing Student Practice for the 21st Century: Educational and Ethical Considerations in Modernizing the District of Columbia Student Practice Rules, 28 GEO. J. LEGAL ETHICS 207 (2015).

${ }^{20}$ This modification would eliminate restrictions that limit many of these licenses to government or public interest workplaces. Those constraints seem unnecessary in the current emergency.

${ }^{21}$ Text of a proposed emergency rule and sample rubrics are available from the authors upon request.

22 NCBE, 2019 PRACTICE ANAlysis (Mar. 2020), https://testingtaskforce.org/wpcontent/uploads/2020/03/TestingTaskForce Phase 2 Report 031020.pdf. The report, for example, lists knowledge of "legal research methodology" as the fifth most important knowledge area - higher than most of the subject areas tested on the bar exam. Id. at 22. Knowledge of "local court rules" ranks seventh. Id. Although the bar exam does not currently test research skills, supervised practice experiences would. Similarly, those experiences are likely to include finding and applying local court rules.
} 
programs. The ABA program allows low-income clients to obtain online legal advice from volunteer lawyers. To adapt this program to emergency licensing, some of those volunteers would agree to supervise participating candidates. Like supervisors in other contexts, they would offer feedback to the candidates and assess their work with rubrics. Candidates would be licensed only if their supervisor(s) affirmed that they had successfully completed the supervised work.

- Notably, this option would allow jurisdictions to license lawyers graduating from law schools in any state. Jurisdictions could specify whether they wanted candidates to perform work within their own state or would accept supervised work performed in other states. Much of the work will be performed online, allowing work and supervision to readily cross state lines.

\section{We Need to Act Now}

The progress of the COVID-19 pandemic makes one point abundantly clear: It is imperative to act quickly and plan ahead. It is already time to make decisions about the July 2020 bar exam. In addition to protecting the public health, we need to preserve the mental health of the candidates hoping to join our profession this year. Those candidates are already suffering educational, family, and financial disruptions. Some have lost part-time jobs needed to support themselves and their families. Others are struggling to care for children or older relatives. All are panicked about whether they will be able to take the bar exam this summer and, if not, how they will cope. Will they be able to find jobs without a law license? Will they study intensely for the bar only to discover that the exam has been cancelled or postponed? This emotional stress is building by the day: some students report that they are struggling to focus on their remaining classes because they are so worried about whether they will be licensed later this year.

We have focused in this paper on the needs of clients and the legal system, because that is the first concern of professionals. As a profession, however, we also have a duty to the students completing their legal studies this spring. As stewards of the legal profession, we need to provide humane options for these new graduates, at the same time that we guarantee a supply of new lawyers to serve pressing client needs.

\section{Further Exploration of Options}

We present options briefly here because time is of the essence; we will expand and refine this document in the coming days. As we do so, we welcome thoughtful input, and are available to discuss solutions with stakeholders grappling with this complex decision. These are unprecedented times and we must work together to ensure we do not leave the talented members of Class of 2020 on the sidelines when we need every qualified professional on the field to keep our justice system moving.

\section{Authors}

Affiliations are included for identification purposes. The analysis here is the professional expression of the authors and not the positions of their institutions.

Claudia Angelos, Clinical Professor of Law, New York University School of Law, claudia.angelos@nyu.edu.

Sara J. Berman, Director of Programs for Academic and Bar Success, AccessLex Institute Center for Legal Excellence, sberman@accesslex.org. 
Mary Lu Bilek, Dean and Professor of Law, CUNY School of Law; Member, Council of the ABA Section on Legal Education and Admission to the Bar, bilek@law.cuny.edu.

Carol L. Chomsky, Professor of Law, University of Minnesota Law School, choms001@umn.edu.

Andrea A. Curcio, Professor of Law, Georgia State University School of Law, acurcio@gsu.edu.

Marsha Griggs, Associate Professor of Law and Director of Academic Support and Bar Passage, Washburn University School of Law, marsha.griggs@washburn.edu.

Joan W. Howarth, Interim Associate Dean for Experiential Legal Education and Distinguished Visiting Professor, William S. Boyd School of Law, University of Nevada at Las Vegas; Dean Emerita, Michigan State University College of Law, joan.howarth@unlv.edu.

Eileen Kaufman, Professor Emerita, Touro College, Jacob D. Fuchsberg Law Center, Ekaufman@tourolaw.edu.

Deborah Jones Merritt, Distinguished University Professor and John Deaver Drinko/Baker \& Hostetler Chair in Law, Moritz College of Law, The Ohio State University, merritt.52@osu.edu.

Patricia E. Salkin, Provost of the Graduate and Professional Divisions, Touro College; Professor of Law, Touro College, Jacob D. Fuchsberg Law Center, Psalkin@tourolaw.edu.

Judith Welch Wegner, Burton Craige Professor of Law Emerita, University of North Carolina School of Law, judith wegner@unc.edu. 